\title{
DEGRADAÇÃO SÓCIO-AMBIENTAL: A CRISE DA ATIVIDADE PESQUEIRA EM JURUJUBA NITERÓI/RJ
}

\section{SOCIO-ENVIRONMENTAL DEGRADATION: THE CRISIS OF THE FISHING ACTIVITY IN JURUJUBA - NITERÓI / RJ}

\author{
Maria Teresa Costa Soares, M.Sc. \\ Mestrado em Sistemas de Gestão / Laboratório de Tecnologia, Gestão de Negócios e Meio \\ Ambiente / Universidade Federal Fluminense / Rua Passo da Pátria 156/329-A, 24210-240 - \\ São Domingos - Niterói - RJ (21) 2625617 ou (21) 27176390 \\ e-mail: mteresa.cs@ terra.com.br
}

Gilson Brito Alves Lima, D.Sc.

Mestrado em Sistemas de Gestão / Laboratório de Tecnologia, Gestão de Negócios e Meio Ambiente / Universidade Federal Fluminense / Rua Passo da Pátria 156/329-A, 24210-240 São Domingos - Niterói - RJ (21) 2625617 ou (21) 27176390 e-mail: gilson@latec.uff.br

André Augusto Pereira Brandão, D.Sc

Professor da Universidade Federal Fluminense / Escola de Serviço Social de Niterói e-mail: aapbuff@globo.com

\section{RESUMO}

Este artigo resulta de uma pesquisa realizada na comunidade pesqueira de Jurujuba. Neste locus, a pesca era desenvolvida pelos pequenos pescadores locais através de know-how tradicional passado de pai para filho, conhecimento este importante para a coleta de forma sustentável dos recursos naturais. Hoje, frente às mudanças ocorridas na pesca, esses pescadores buscam outras ocupações visando a sua subsistência. Através dos dados quantitativos resultantes da aplicação de questionários sócio-econômicos e da análise das entrevistas realizadas, mapeou-se as características relacionadas aos aspectos econômicos de trabalho e renda da população, e as formas subjetivas pelas quais o grupo percebe a crise na pesca e o processo de dissolução identitária do grupo. Tais resultados apontam para um reduzido número de moradores que ainda trabalham na pesca em Jurujuba e o reduzido peso da atividade pesqueira na reprodução sócio-econômica do grupo. Verifica-se que o grupo identifica na poluição e na sobrepesca os determinantes da crise da atividade e recomenda-se 
que atuais ou futuros projetos para a recuperação da Baía de Guanabara, ou da atividade pesqueira, levem em consideração o "saber local", construído pelos agentes sociais que se reproduzem naquele ecossistema.

Palavras-chave: Pesca de subsistência. Poluição. Identidade.

\begin{abstract}
This article is a result of a research carried out at Jurujuba's fishing community. In that locus, the local fishermen used to apply the know-how passed from parent to offspring in their fishing activities which was important for a sustainable exploitation of natural resources. Nowadays, due to changes on fishing practices, those fishermen pursue other occupations as a way of subsistence. Based on quantitative data come by socio-economic questionnaires applied and analysis of interviews carried out, was designed a map of the characteristics related to economic aspects of labour and income in that community, and the subjective way the group perceives crisis in the fishing activity and the dissolution process of their identity. Results pointed to a reduced number of dwellers that still dedicate to fishing at Jurujuba and the reduced weightiness of fishing in the group's socio-economic reproduction. Data also indicate that the group identifies pollution and over-fishing as determining factors for crisis in the activity. As a recommendation, current or future projects for recovery of Guanabara Bay or fishing activity should take into account "local knowledge" built by social agents reproduced in that ecosystem.
\end{abstract}

Key-words: Fishing. Pollution. Identity

\title{
1 - O MACRO CONTEXTO
}

$\mathrm{O}$ artigo desenvolvido, que toma a comunidade pesqueira de Jurujuba como alvo, inicioutse a partir da intervenção apresentada por DUARTE (1978) onde buscou-se avaliar a participação percentual do contingente de pescadores total do bairro objeto da pesquisa. Partese da constatação de que neste locus, a pesca, de um modo geral, era circunscrita à comunidade local dos pequenos pescadores; ou seja, não se fazia uso de mão-de-obra assalariada e desta forma, a pesca como meio de subsistência constituía o objetivo fundamental das atividades pesqueiras locais. (DIEGUES, 1983).

A comunidade de Jurujuba, que possuía traços semelhantes aos das "comunidades tradicionais" (DIEGUES, 1994), baseava-se economicamente no uso dos recursos naturais renováveis da Baía de Guanabara, através da pesca artesanal. Esta atividade era desenvolvida através de know-how tradicional transmitido, de geração em geração; conhecimento este de grande importância para a coleta, de forma sustentável, desses recursos naturais.

Em SOARES (2003) consolida-se que hoje, frente ao desequilíbrio ecológico para o qual colaborou não só a sobrepesca como também a poluição proveniente dos dejetos urbano- 
industriais, esses pescadores que tinham na exploração do ecossistema aquático local a sua fonte de renda passam a buscar novas formas de relação com o trabalho, no sentido de viabilizar sua reprodução familiar. Não fosse a degradação de seus recursos naturais, a Baía de Guanabara continuaria possibilitando a pesca como atividade econômica de subsistência da comunidade local de Jur ujuba, e viabilizando perspectivas de capitalização e desenvolvimento da atividade.

Da mesma forma, a inserção de meios de pesca mais poderosos e mecanizados, tanto para os fins de navegação quanto para a captura do pescado, contribui aqui para o afastame nto do pequeno pescador dos seus instrumentos de trabalho, de sua experiência, conhecimento, e do domínio sobre o processo de trabalho (DIEGUES, 1983), na medida em que este não possuía a disponibilidade de capital necessária para a aquisição desses meios de pesca mais caros.

Os pescadores artesanais se identificam como um grupo que possui profissão, entendida aqui como o domínio de um conjunto de conhecimentos e técnicas que permitem ao produtor subsistir e se reproduzir enquanto pescador. (DIEGUES, 1983)

A partir de Bosi (1998), constata-se que a identidade cultural de um grupo se constrói por sobre as relações materiais que os homens empreendem para sua reprodução social. Desta forma, a comunidade pesqueira de Jurujuba tinha a sustentação de sua identidade calcada na utilização do meio, a Baía de Guanabara: sua identidade, portanto, se estruturava no próprio meio de produção econômica e reprodução da vida material e social. O desenvolvimento da pesca neste "território" (espaço determinado pelo meio físico explorado e pelas relações sociais e econômicas nele existentes), possibilitava ao pescador não somente viver da pesca, mas sobretudo apropriar-se dos meios de produção e ter "o controle de como pescar e do que pescar, em suma, o controle da arte da pesca." (DIEGUES, 1983, p.198)

Hoje, frente à impactação da Baía de Guanabara, este cenário se modifica, acarretando impactos sociais na comunidade, ou seja, na história da reprodução sócio-cultural de um grupo que tem uma base econômica ligada ao meio e cujo locus de reprodução não mais possibilita a sua atividade econômica como meio de subsistência.

Atualmente, esta comunidade não mais obtém da pesca artesanal, os seus meios de subsistência o que leva boa parte dos moradores a buscarem outras formas de sobrevivência. Seja trabalhando em traineiras, ou até mesmo abandonando a profissão; alimentando conseqüentemente, as franjas mais pauperizadas do emprego urbano e do desemprego.

A comunidade de Jurujuba, portanto, constitui um locus interessante para um estudo que se proponha a colaborar com a compreensão de processos dinâmicos de inter-relação entre: meio ambiente e economia, meio ambiente e relações de trabalho e meio ambiente e reprodução 
social de comunidades pesqueiras.

Frente à impactação de sua unidade de ecursos, os pescadores migraram para um novo contexto técnico e de relações de trabalho em que são utilizados novos instrumentos e cuja forma de acumulação e transmissão de capital diferem ao extremo da forma tradicional com que vinham sendo praticados pela população local. Muitos deles ficam sujeitos a abandonar a profissão sendo inseridos no contexto do mercado de trabalho urbano e do desemprego. Além disto, há uma perda de identidade social da comunidade, na medida em que se reduz o peso da atividade pesqueira na reprodução sócio-econômica do grupo.

Este estudo se limitou à população de Jurujuba e sua relação com o meio de subsistência próximo. Não se avaliou as características biológicas do impacto da Baía pela poluição e pela sobrepesca. Não estarão aqui igualmente, sendo tomadas como objeto as fontes de tal impacto. Outrossim, a preocupação está na forma como a comunidade sentiu e se adaptou à degradação ambiental.

Assim, a pesquisa persegue dois pontos principais: a) a identificação de como o impacto ambiental desestrutura formas consolidadas de reprodução econômica e impede o possível desenvolvimento destas; e b) o mapeamento de como as populações atingidas reagem e constroem novas estratégias de sobrevivência.

Acredita-se que é fundamental demonstrar o custo social conseqüente dos efeitos da inexistência, ou ineficiência de uma política ambiental atuante. Acredita-se também que é importante demonstrar que caso houvesse uma perspectiva de equilíbrio ambiental, haveria possibilidade de reprodução econômica e desenvolvimento sustentável de pequenos aglomerados populacionais. Ambos aspectos constituem pontos que podem ser utilizados em futuras atividades de formulação e gestão de políticas públicas e privadas.

O objetivo mais geral da pesquisa realizada consiste em contribuir com o conhecimento acerca dos processos adaptativos (sociais, econômicos e técnicos) da comunidade pesqueira de Jurujuba frente à degradação de seus recursos naturais.

Mais especificamente, busca-se compreender na história social do grupo, as técnicas e as relações de trabalho no que tange à atividade pesqueira e às mudanças nestas, frente à impactação da Baía de Guanabara; bem como compreender as mudanças nos processos identitários da comunidade pesqueira de Jurujuba.

\section{2 - A CARACTERIZAÇÃO SÓCIO-ECONÔMICA DA POPULAÇÃO DE JURUJUBA}

A partir da análise de dados quantitativos obtidos com a aplicação de 249 questionários, em 
uma amostra de famílias no bairro de Jurujuba em Niterói/RJ, buscourse traçar um perfil da população pescadora de Jur ujuba.

O bairro de Jurujuba subdivide-se em localidades, e segundo a estimativa do Programa Saúde da Família (PSF), que lá atua, existiam cerca de 1173 famílias, em 2002.

A entrada no campo foi feita através da Associação de Moradores local e teve início em março de 2002. A composição do questionário fechado, que constituiu o instrumento de coleta de dados, foi realizada em conjunto com a Associação. Vale ressaltar que a proposta inicial de questionário de coleta de dados veio a incluir variáveis que foram demandadas pela Associação. Para a elaboração do levantamento sócio-econômico do bairro de Jurujuba, foi feito um projeto de extensão comunitária institucional através da Universidade Federal Fluminense (UFF), onde os autores desse trabalho fazem parte do quadro docente. Para a aplicação dos questionários sócio-econômicos, contou-se com a participação de um aluno bolsista de extensão da UFF. Adotou-se como critério, aplicar os questionários em $20 \%$ dos domicílios de cada localidade.

Na medida em que o bairro de Jurujuba é constituído de morros, definiu-se que a pesquisa seria feita seguindo as ruas, desde a sua parte mais baixa, até o seu ponto mais alto, uma vez que os domicílios que se encontram na rua principal, e portanto na parte mais baixa do morro, apresentam melhores condições, inclusive de saneamento, diferindo dos demais domicílios situados ao longo da subida dos morros.

Com esses questionários buscou-se identificar características sócio-econômicas atuais da população. Desta forma procuroutse apreender as seguintes informações: composição da família; distribuição etária; tempo de residência; escolaridade; ocupação; renda; desemprego e tempo de desemprego.

Os dados quantitativos, oriundos desses questionários, foram obtidos, portanto, desagregados por áreas, e sua coleta estendeu-se até junho de 2002. Foram tabulados através de cruzamentos realizados no programa SPSS, contando com a assessoria do Departamento de Estatística da UFF.

A amostra dos domicílios indicou que os núcleos familiares constituíam-se, em média, de 3,33 pessoas, o que permite uma estimativa de 3906 habitantes para a população do bairro $(3906 \pm 136$ habitantes, com $95 \%$ de confiança).

Nesta primeira Tabela abaixo pode-se observar a proporção da População Economicamente Ativa (PEA) do bairro de Jurujuba. Ao somar-se os indivíduos que trabalham e aqueles que procuram emprego, percebe-se que eles atingem a proporção de $51,3 \%$ a $58,3 \%(54,8 \% \pm$ $3,5 \%$, com $95 \%$ de confiança) da população local. Nos demais se encontram não somente 
indivíduos dependentes economicamente dos indivíduos ativos como também os aposentados. Estes últimos, na população, estão entre $13,1 \%$ e $20,9 \%(17 \% \pm 3,9 \%$, com $95 \%$ de confiança) dos não economicamente ativos.

Tabela 1 - Jurujuba - Número de indivíduos, segundo a inserção em atividade econômica - 2002

\begin{tabular}{llcc}
\hline \hline \multirow{2}{*}{ Inserção em atividade econômica } & Número de indivíduos & Percentual \\
\hline \multirow{2}{*}{ PEA } & Trabalhando & 355 & 44,8 \\
\cline { 2 - 4 } & À procura de emprego & 79 & 10,0 \\
\hline \multirow{2}{*}{ Total } & Economicamente inativos & 359 & 45,2 \\
\hline \hline
\end{tabular}

Fonte: (SOARES, 2003)

$\mathrm{O}$ número total de indivíduos que ainda se encontra vinculado à pesca, na PEA do bairro, pode ser percebido na Tabela 2 seguinte. Como se vê, o número de pescadores na PEA é bastante pequeno, se levar-se em conta que Jurujuba é considerada ainda uma "comunidade de pescadores". Estima-se, com os dados obtidos na amostra, que o total de pescadores esteja, com $95 \%$ de confiança, entre $5,7 \%$ e $8,5 \%(7,1 \% \pm 1,4 \%)$ da população total do bairro, o que permite concluir que, em média, existem aproximadamente 275 pescadores em Jurujuba, pertencentes à cerca de 85 domicílios. Talvez este dado explique o fato de que a própria sede da Colônia de Pesca Z08 encontra-se fechada, em estado de abandono e a Associação de Pescadores local encontra-se em processo de reativação nos dias atuais.

No entanto, a imagem que o bairro tenta projetar para o conjunto do Município ainda se vincula à idéia de uma comunidade pesqueira. Um exemplo disto encontra-se na festa do Padroeiro da mesma, "São Pedro", realizada no mês de junho. Nesta ocorre uma procissão de barcos e na festa realizada no ano de 2003 encontrou-se um espaço reservado àqueles que teriam feito a história da pesca no local.

Assim, a imagem que a comunidade projeta se assemelha a uma performance discursiva que não se concretiza nos dados encontrados nesta pesquisa. 
Tabela 2 - Jurujuba - Número de pescadores no total da PEA identificados na amostra - 2002

\begin{tabular}{ccc}
\hline \hline & Número de pessoas & Percentual \\
\hline Pescadores & 56 & 12,9 \\
Não pescadores & 378 & 87,1 \\
Total & 434 & 100,0 \\
\hline \hline
\end{tabular}

Fonte: (SOARES, 2003)

Dentre o número de pescadores encontrados na amostra, pode-se dizer, conforme demonstrado na Tabela 3 a seguir, que 78,6\% deles são chefes de família, 1,8\% são cônjuges de chefes de família, e menos de $20 \%$ são filhas ou filhos. Isto parece indicar que os pescadores são em geral indivíduos de maior idade que já constituíram suas famílias. Além disto, parece não estar ocorrendo um processo de continuidade da atividade pesqueira dentro dos núcleos familiares.

Os dados obtidos apontaram ainda para o fato de que somente $18 \%$ dos pescadores passam para seus filhos a hereditariedade na pesca, ou seja, têm filhos trabalhando na pesca.

Tabela 3 - Jurujuba - Pescadores segundo a tipificação de membro da família -

2002

\begin{tabular}{ccc}
\hline \multirow{2}{*}{ Classificação do membro da família } & $\begin{array}{c}\text { Número de } \\
\text { pescadores }\end{array}$ & Percentual \\
\cline { 2 - 2 } & & \\
\hline Chefe de família & 44 & 78,6 \\
Cônjuge & 1 & 1,8 \\
Filho/filha & 11 & $\underline{19,6}$ \\
Total & 56 & 100,0 \\
\hline \hline
\end{tabular}

Fonte: (SOARES, 2003)

Observando-se a idade desses chefes de família que se dizem pescadores na amostra, constata-se, conforme Gráfico 1 abaixo, que a média alcança pouco menos de 50 anos. 


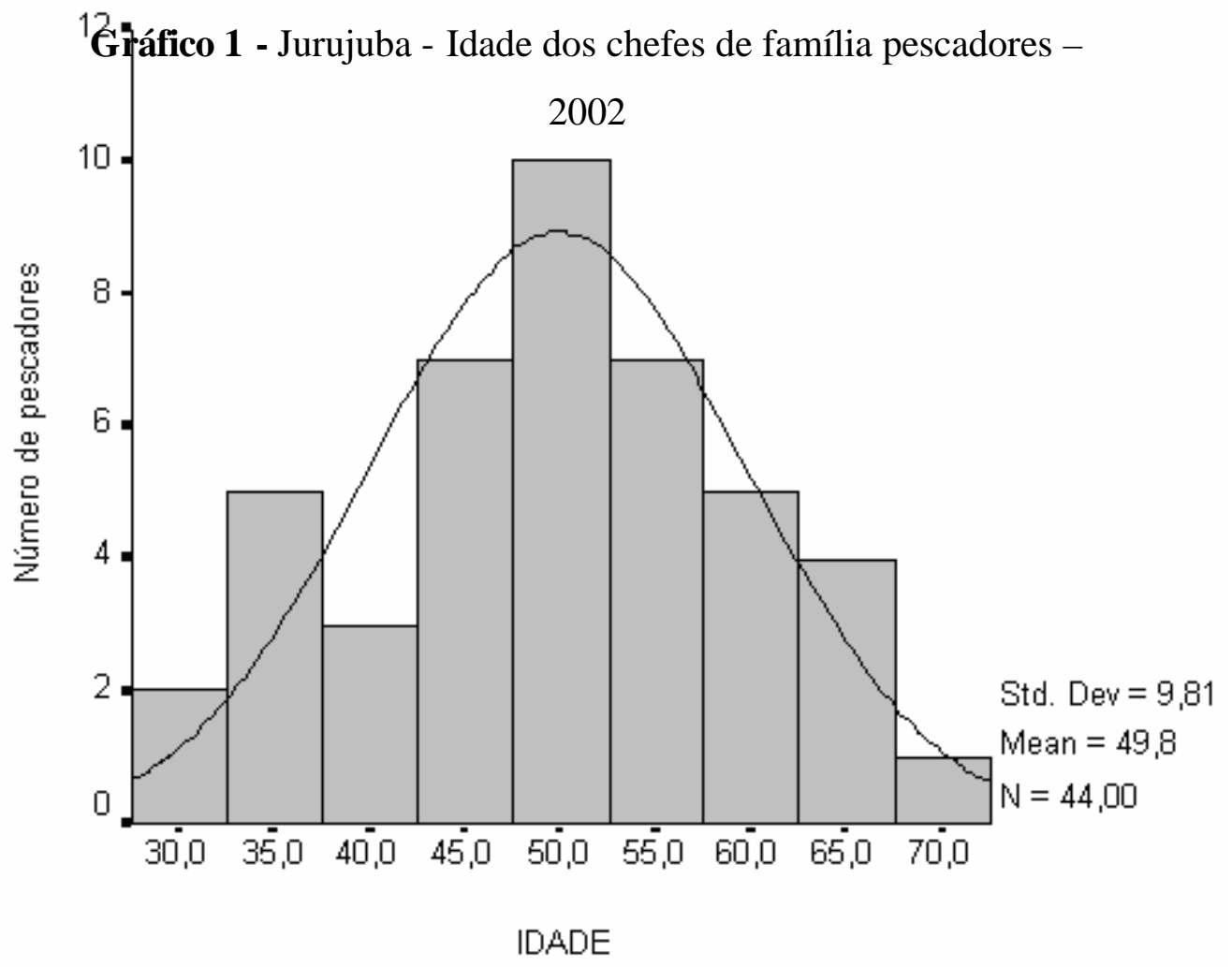

Fonte: (SOARES, 2003)

Quanto à idade dos filhos que são pescadores, identificados na amostragem, pode-se perceber no Gráfico 2 seguinte, que a sua média encontra-se em pouco mais de 25 anos. É nesta idade que se concentra a parte mais significativa destes, o que corrobora as assertivas apresentadas anteriormente, pois poucos são os filhos de pescadores em idade mais jovem. 
4,0

Gráfico 2 - Jurujuba - Idade dos filhos pescadores - 2002

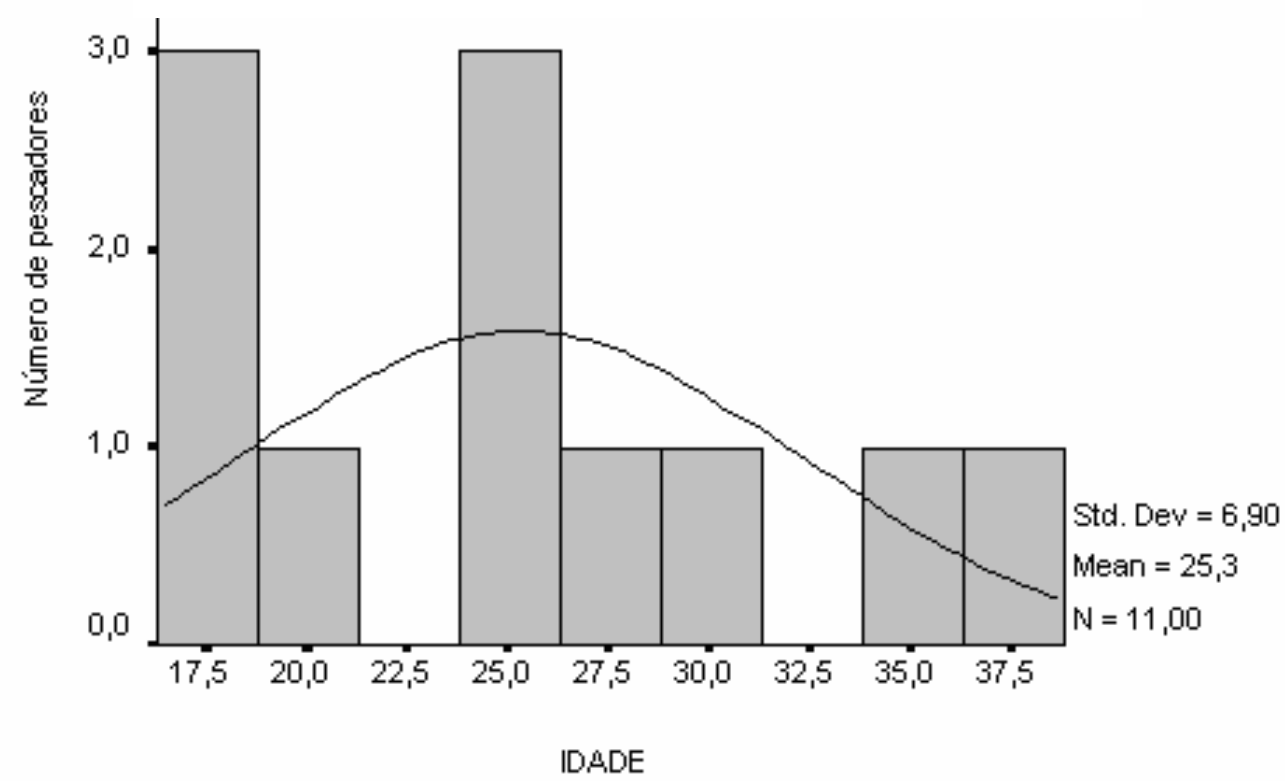

Fonte: (SOARES, 2003)

No entanto, ao verificar-se a idade de todos os pescadores da população pesquisada, pode-se notar, no Gráfico 3 a seguir, que a média fica pouco abaixo dos 45 anos. Porém existe uma sobreposição da idade dos pais com a dos filhos, na faixa dos 35 anos. Os dois picos neste Gráfico evidenciam a existência de dois grupos de pescadores: os pais com a idade modal em torno dos 50 anos e os mais jovens (incluindo os filhos) com a concentração em torno dos 35 anos de idade. 


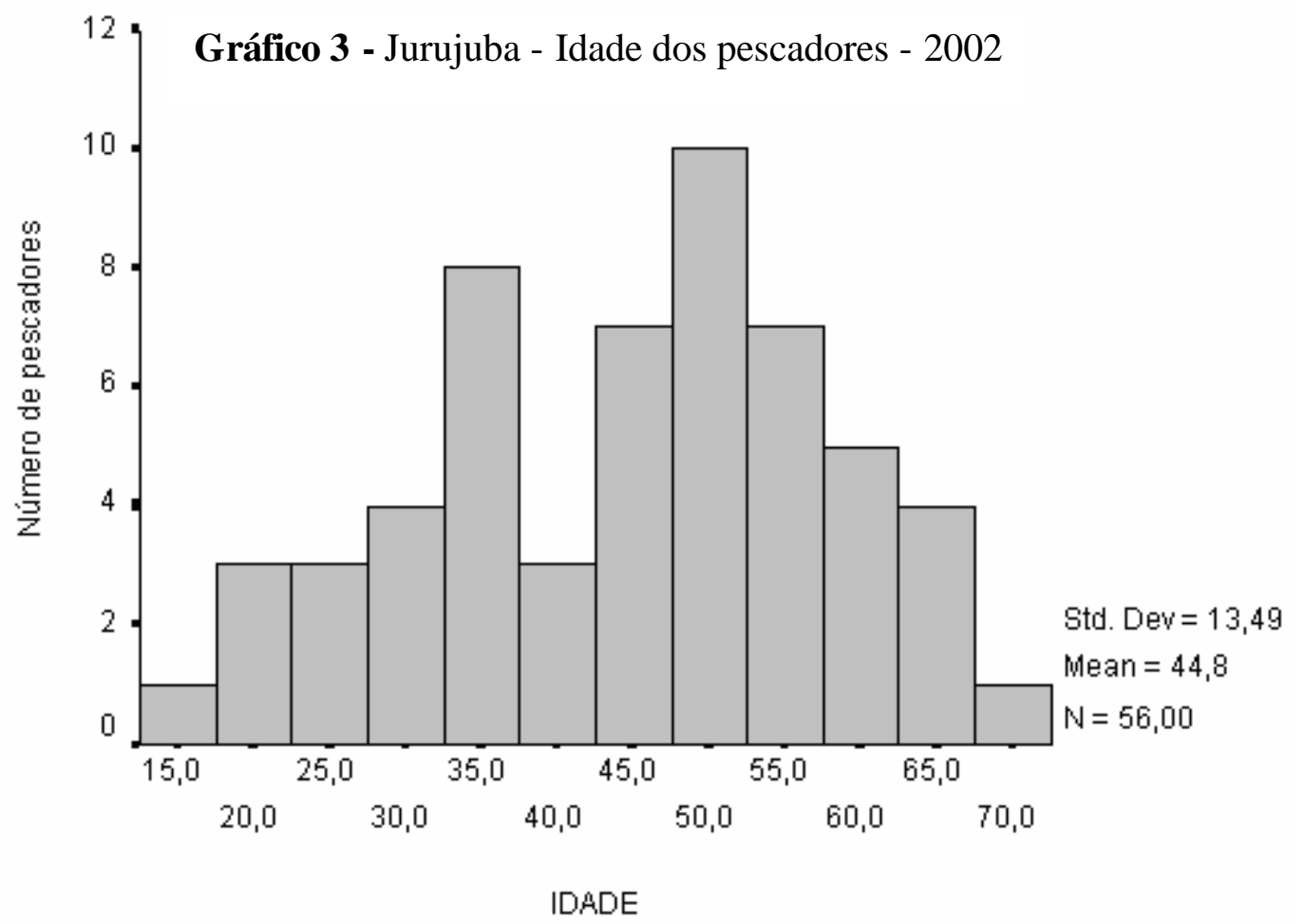

Fonte: (SOARES, 2003)

Quanto ao sexo, vê-se na Tabela 4 abaixo que a grande maioria dos chefes de família da comunidade é do sexo masculino, acompanhando uma tendência nacional.

Tabela 4 - Jurujuba - Chefes de família, segundo o sexo - 2002

\begin{tabular}{lcc}
\hline \hline Sexo & $\begin{array}{c}\text { Número de Chefes de } \\
\text { família }\end{array}$ & $\begin{array}{c}\text { Freqüência } \\
\text { percentual }\end{array}$ \\
\hline masculino & 219 & 88,0 \\
feminino & 30 & 12,0 \\
Total & 249 & 100,0 \\
\hline \hline
\end{tabular}

Fonte: (SOARES, 2003)

Ao se averiguar a situação dos chefes de família de acordo com a sua ocupação, percebe-se, na Tabela 5 seguinte, que de 13,0\% a 22,4\% (17,7\% \pm 4,7\% com 95\% de confiança) deles trabalham na atividade pesqueira, indicando o pequeno peso da pesca como atividade econômica que viabiliza a reprodução material das famílias que ali residem. 
Tabela 5 - Jurujuba - Chefes de família, segundo a ocupação com a pesca -

2002

Jurujuba - Chefes de família, segundo a ocupação com a pesca - 2002

\begin{tabular}{|c|c|c|}
\hline & Número de chefes de família & Freqüência percentual \\
\hline Pescador & 44 & 17,7 \\
\hline Não-pescador & 205 & 82,3 \\
\hline Total & 249 & 100,0 \\
\hline
\end{tabular}

Fonte: (SOARES, 2003)

Dentre esses chefes de família que trabalham na pesca, constata-se, conforme Tabela 6 abaixo, que $45,5 \%(45,5 \% \pm 12,4 \%$, com $95 \%$ de confiança na população de pescadores $)$ deles trabalham também em uma segunda atividade. Este dado mostra, mais uma vez, o quanto a atividade pesqueira não mais caracteriza o bairro, pois além de somente cerca de $17,7 \%$ dos chefes de família serem pescadores, por volta da metade destes desenvolvem outra atividade remunerada.

Tabela 6 - Jurujuba - Chefes de família pescadores, conforme a existência de uma segunda ocupação - 2002

\begin{tabular}{ccc}
\hline \hline & $\begin{array}{c}\text { Número de chefes } \\
\text { de família }\end{array}$ & $\begin{array}{c}\text { Freqüencia } \\
\text { percentual }\end{array}$ \\
\hline Pescador com segunda ocupação & 20 & 45,5 \\
Pescador sem segunda ocupação & 24 & 54,5 \\
Total & 44 & 100,0 \\
\hline \hline
\end{tabular}

Fonte: (SOARES, 2003)

Quanto à renda individual dos que declararam ter a pesca como única fonte de renda, o Gráfico 4 a seguir indica que a média de rendimentos destes alcança $R \$ 276,00$. A concentração maior se encontra na faixa entre $R \$ 250,00$ e $R \$ 300,00$; seguida da faixa de $\mathrm{R} \$ 300,00$ e $\mathrm{R} \$ 350,00$. Um número muito pequeno de indivíduos recebe renda maior que $\mathrm{R} \$ 350,00$.

Vale ressaltar que dos 39 indivíduos que declararam ter a pesca como única ocupação, 35 deles apresentaram renda relacionada à atividade pesqueira, 2 deles se declararam 
desempregados e outros 2 não declararam renda recebida.

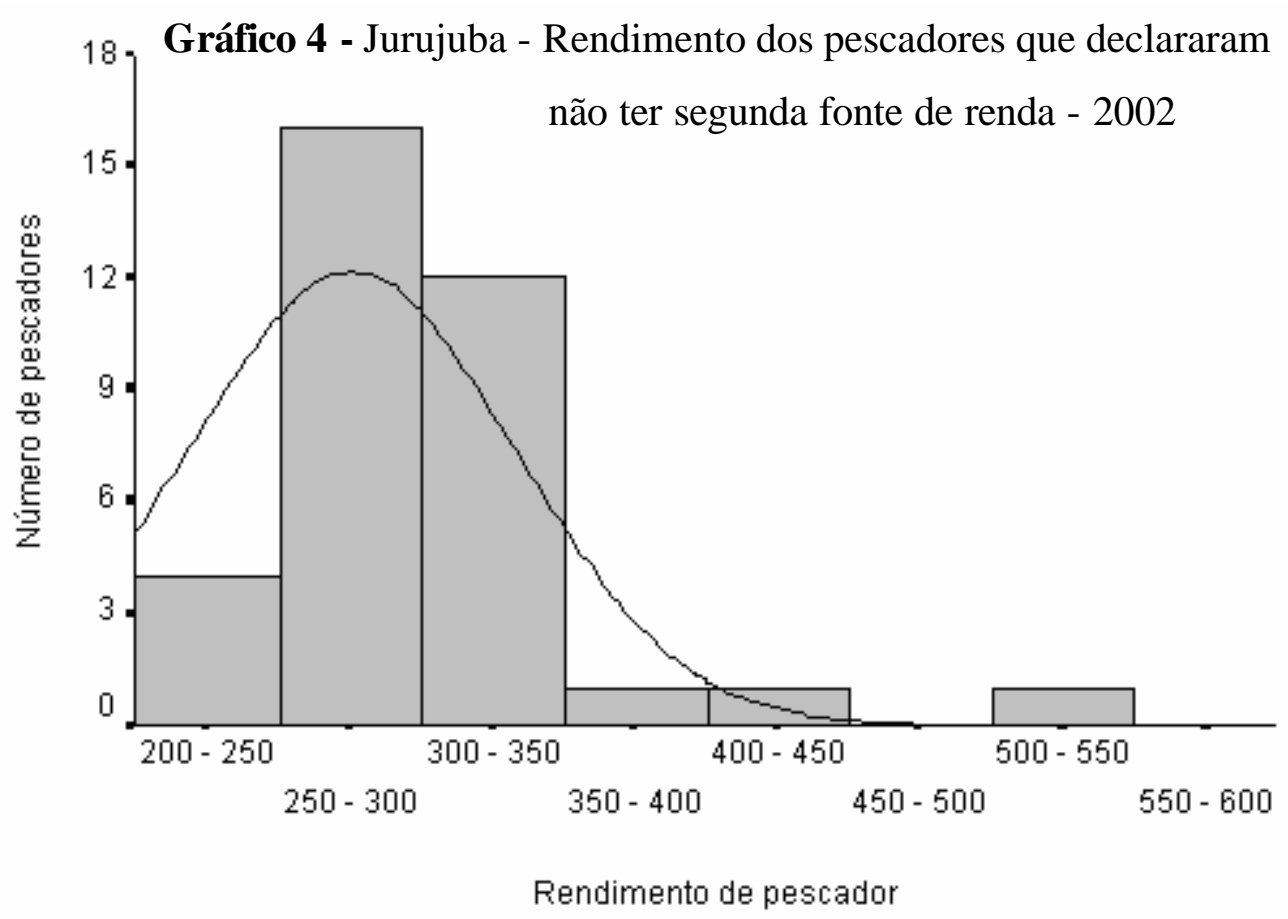

Média de rendimentos: $\mathrm{R} \$ 276,00$ (desvio padrão: $\mathrm{R} \$ 57,36$ )

Número de pescadores na amostra: 35

Coeficiente de variação: $20,78 \%$

Fonte: (SOARES, 2003)

Considerando-se os indivíduos que possuem renda proveniente tanto da atividade pesqueira quanto de uma segunda ocupação, o Gráfico 5 a seguir permite fazer algumas observações.

Constata-se que dos 56 trabalhadores que se declararam pescadores, 17 deles têm renda proveniente de uma segunda ocupação, incluídos aí, 2 casos de renda de aposentadoria. Já quanto aos trabalhadores que declararam ter uma segunda ocupação, 5 deles não apresentam a renda da segunda ocupação declarada. Como se vê, a média de rendimentos deste grupo alcança $\mathrm{R} \$ 538,00$. Estes se concentram em três faixas de renda: $\mathrm{R} \$ 450,00$ - $\mathrm{R} \$ 500,00$; $\mathrm{R} \$ 550,00$ - $\mathrm{R} \$ 600,00$ e $\mathrm{R} \$ 600,00$ - $\mathrm{R} \$ 650,00$. Vê-se ainda que um pequeno número destes chega a alcançar rendimentos entre $\mathrm{R} \$ 750,00$ e $\mathrm{R} \$ 800,00$. Quando se compara os Gráficos 4 e 5, vê-se que a segunda ocupação eleva substancialmente a renda individual do pescador.

A partir dos dados obtidos, foi possível tecer algumas conclusões em relação à média da renda per capita, nos domicílios nos quais o chefe de família se declarou pescador. Pode-se perceber que quando o chefe de família é pescador e não tem uma segunda ocupação, a média encontrada é $\mathrm{R} \$ 188,71$ - (total de 20 casos). Para os que têm uma segunda ocupação, a 
média encontrada é $\mathrm{R} \$ 172,17$ - (total de 20 casos). Há quatro casos sem referência de renda per capita, uma vez que o dado sobre a renda não foi fornecido nesses quatro domicílios.

Pode-se observar que não há diferença estatisticamente significativa entre a renda per capita das famílias nas quais o chefe não tem uma segunda ocupação e a daquelas onde o chefe possui uma segunda ocupação (teste $t$ de Student $t=-0,622 ; p>0,05$ ); assim a renda de ambos os grupos se equivale. Talvez isso se deva ao fato de que em famílias maiores existe a tendência a que o chefe complemente a renda obtida como pescador com outra atividade remunerada.

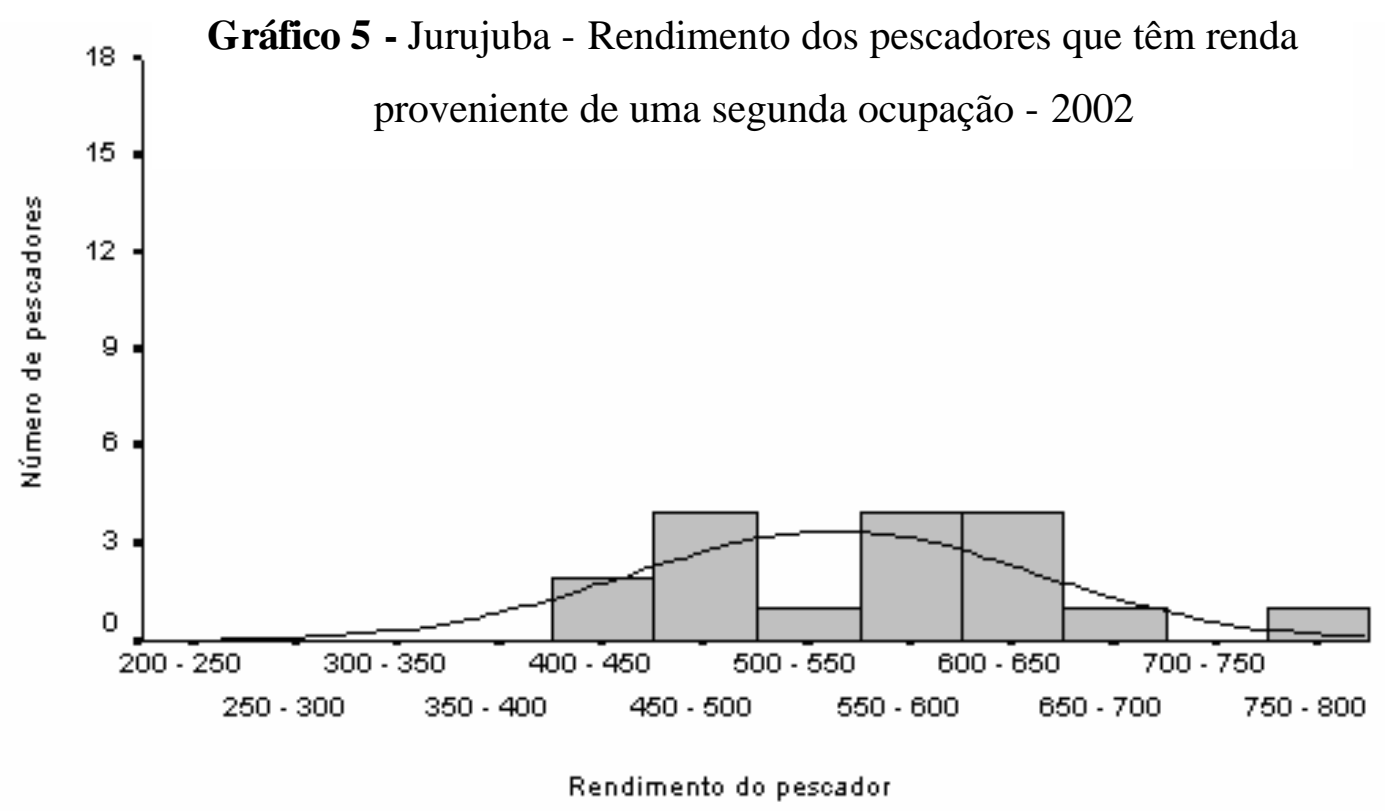

Média de rendimentos: $\mathrm{R} \$ 538,00$ (desvio padrão : $\mathrm{R} \$ 99,03$ )

Número de pescadores na amostra: 17

Coeficiente de variação: $18,41 \%$

Fonte: (SOARES, 2003)

No entanto, ao se averiguar a renda obtida por aqueles trabalhadores que não atuam na pesca, constata-se, no Gráfico 6 seguinte, que a média de renda aqui chega a $\mathrm{R} \$ 338,00$. A concentração está na faixa de $R \$ 200,00$ a $R \$ 300,00$; seguida pela faixa entre $R \$ 300,00$ e $\mathrm{R} \$ 400,00$. Alguns indivíduos atingem a faixa entre $\mathrm{R} \$ 900,00$ e $\mathrm{R} \$ 1000,00$. 


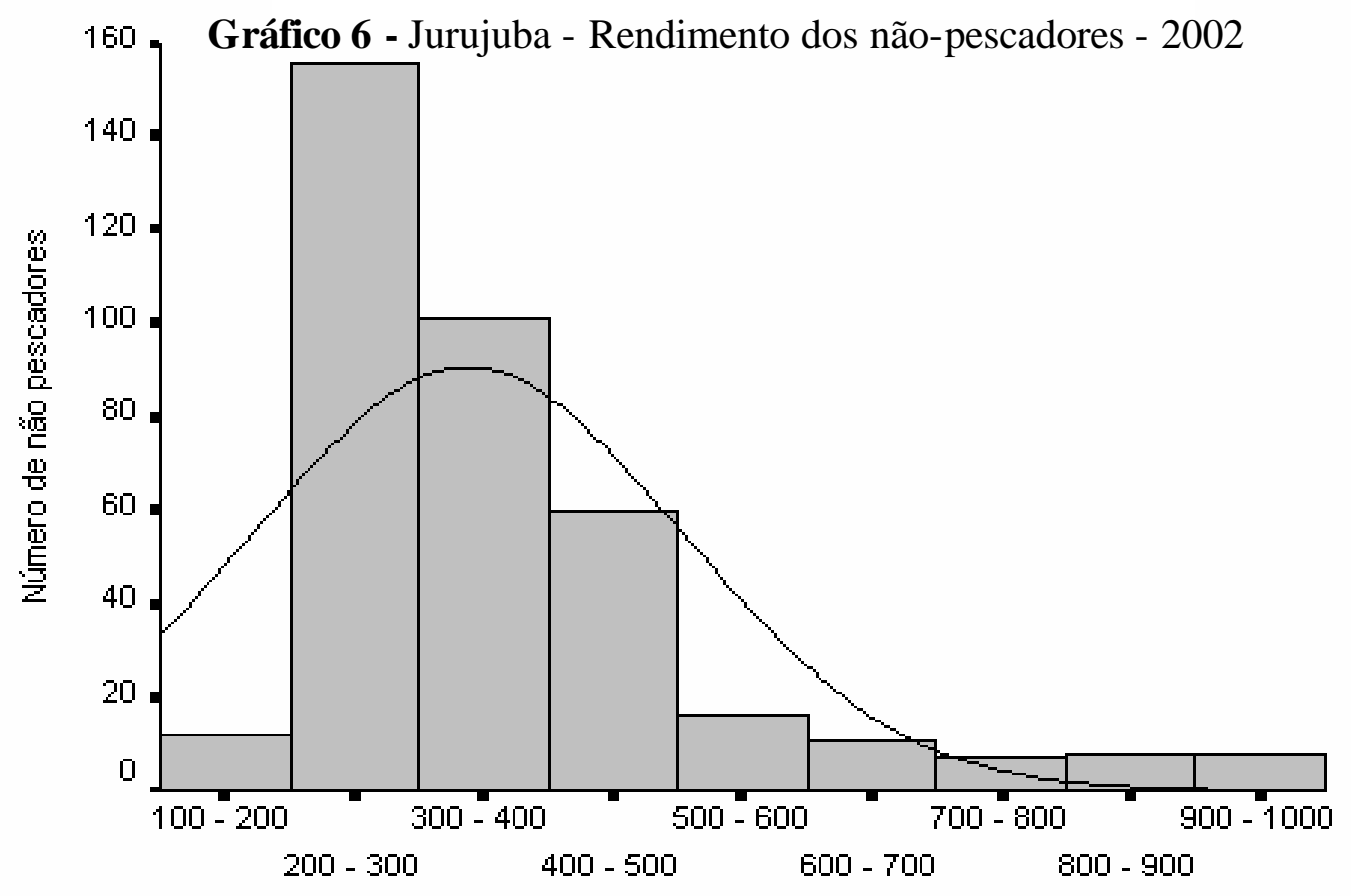

Rendimento dos nẫo pescadores

Média

de rendimentos: $\mathrm{R} \$ 338,00$ (desvio padrão : $\mathrm{R} \$ 166,47$ )

Número de não-pescadores na amostra: 378

Coeficiente de variação $=49,25 \%$

Fonte: (SOARES, 2003)

Observando-se os Gráficos 4, 5 e 6, pode-se concluir que na média de renda, os nãopescadores ficam acima dos que somente são pescadores, mas abaixo daqueles que agregam outra atividade à pesca.

Por outro lado, o Gráfico 7 a seguir indica que a renda obtida pela segunda ocupação dos pescadores é tanto menor quanto maior for a sua renda de pescador. Pode-se levantar a hipótese segundo a qual quanto mais o pescador se dedica à pesca e nela obtém uma melhor remuneração, menos tempo tem para dedicar-se a uma segunda ocupação e conseqüentemente conseguir uma melhor remuneração nesta atividade. 
Gráfico 7 - Jurujuba - Relação entre a renda da pesca e a renda adicional dos

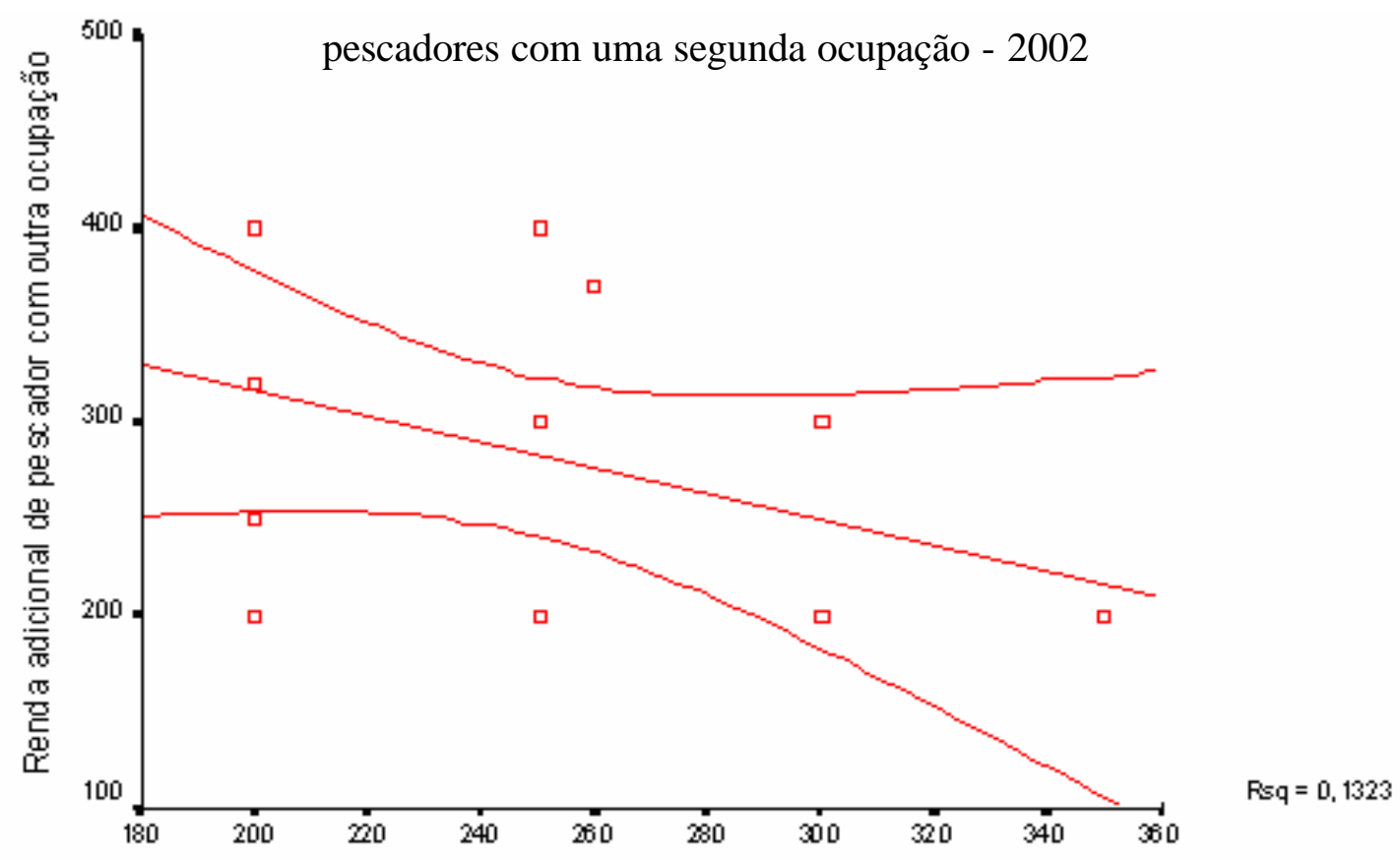

Rendimento de pescador

Fonte: (SOARES, 2003)

Quanto ao nível de escolaridade, pode-se perceber na Tabela 7 abaixo, que entre 87,5\% e $98,3 \%(92,9 \% \pm 5,4 \%$, com $95 \%$ de confiança) está a proporção de pescadores que possuem o ensino fundamental ou começaram a cursá-lo, enquanto que no máximo 4,6\% $(1,8 \% \pm 2,8 \%$, com $95 \%$ de confiança) chegaram ou concluíram o ensino médio.

Tabela 7 - Jurujuba - Escolaridade dos pescadores - 2002

\begin{tabular}{ccc}
\hline \hline Escolaridade & Número de pescadores & Percentui \\
\hline ensino médio & 1 & 1,8 \\
ensino fundamental & 52 & 92,9 \\
não declarada & 3 & 5,3 \\
Total & 56 & 100,0 \\
\hline \hline
\end{tabular}

Fonte: (SOARES, 2003)

Ao se averiguar a escolaridade dos chefes de família que trabalham na atividade pesqueira, constata-se na Tabela 8 a seguir, que nenhum deles alcançou o ensino médio. Dentre eles, $76,2 \%$ (entre $65,2 \%$ e $87,2 \%$, com $95 \%$ de confiança na população) possuem somente o primeiro segmento do ensino fundamental, enquanto que $23,8 \%$ (entre $12,8 \%$ e $34,8 \%$, com 
95\% de confiança para a população) alcançaram o segundo segmento.

Tabela 8 - Jurujuba - Escolaridade dos chefes de família pescadores -

2002

\begin{tabular}{ccc}
\hline \hline Escolaridade & $\begin{array}{c}\text { Número de chefes de } \\
\text { família }\end{array}$ & Percentual \\
\hline Ensino Fundamental (5a. a 8a. série) & 10 & 23,8 \\
Ensino Fundamental (1a. a 4a. série) & 32 & 76,2 \\
Total & 42 & 100,0 \\
\hline \hline
\end{tabular}

Fonte: (SOARES, 2003)

Quanto ao nível de escolaridade dos chefes de família que não trabalham na pesca, pode-se observar, conforme a Tabela 9 abaixo, que $73,9 \%$ deles $(73,9 \% \pm 2,0 \%$ na população, com $95 \%$ de confiança) possuem apenas o ensino fundamental, $23,0 \%(23,0 \% \pm 1,9 \%$ na população) possuem o ensino médio e $0,5 \%$ (de $0,2 \%$ a $0,8 \%$ na população, com $95 \%$ de confiança) tem nível superior. Vê-se assim, que a escolarização média dos chefes de família que não trabalham como pescadores é muito mais elevada que a dos chefes de família pescadores.

Tabela 9 - Jurujuba - Escolaridade dos chefes de família não-pescadores - es 2002

\begin{tabular}{lcc}
\hline \hline \multicolumn{1}{c}{ Escolaridade } & Número de chefes de familia & Percentual \\
\hline ensino superior & 1 & 0,5 \\
ensino médio & 43 & 23,0 \\
ensino fundamental & 138 & 3,8 \\
alfabetização & 4 & 2,1 \\
analfabeto & 1 & 0,5 \\
Total & 187 & 100,0 \\
\hline \hline
\end{tabular}

Fonte: (SOARES, 2003) 
Constata-se ainda, como se vê na Tabela 10 a seguir, que dentre as localidades que compõem o bairro de Jurujuba, Cascarejo é aquela que apresenta o maior número de chefes de família que trabalham na atividade pesqueira. Talvez isso se deva a sua localização, próxima do final do bairro, e conseqüentemente mais próxima das áreas onde tradicionalmente ocorrem as saídas de barcos e baleeiras para a pesca.

Tabela 10 - Jurujuba - Distribuição dos chefes de família pescadores, segundo a localidade 2002

\begin{tabular}{lc}
\hline \hline Localidade & Percentual \\
\hline Salina & 11,4 \\
Peixe Galo & 13,6 \\
Pau Ferro & 11,4 \\
Jurujuba & 6,8 \\
Cascarejo & 38,6 \\
Canguna & 18,2 \\
Total & 100,0 \\
\hline \hline
\end{tabular}

Fonte: (SOARES, 2003)

\section{3 - ANÁLISE DA PESQUISA E RESULTADOS OBTIDOS}

Após a realização das atividades de pesquisa de campo e da organização e análise dos dados quantitativos e qualitativos coletados, chegou-se ao conjunto de resultados expostos a seguir. De início vale ressaltar que o contingente de pescadores entre a população total no bairro é muito pequeno. Na década de 70 segundo Duarte (1978), Jurujuba tinha aproximadamente $25 \%$ de pescadores entre os residentes. O resultado desta pesquisa aponta somente $7,1 \%$ de pescadores na população total do bairro, o que corresponde a $12,9 \%$ da população economicamente ativa ali residente e a $17,7 \%$ dos chefes de família. Esta tão acentuada diminuição indica que o bairro perdeu em duas décadas sua tipicidade de "comunidade de pescadores" e hoje abarca uma grande maioria de moradores que se aproximam ocupacionalmente dos moradores de outros bairros pobres de Niterói. Esta afirmação pode ainda ser referendada pelo fato de que atualmente, 45,5\% do total de chefes de família que pescam, também atuam em uma segunda ocupação. Para além disto, ao calcular-se a renda 
individual média dos chefes de família que trabalham em ocupações diferentes da pesca e dos que são somente pescadores, pode-se verificar que os chefes não-pescadores recebem em média salários $18 \%$ maiores que os chefes pescadores. Houve uma redução significativa no número de pescadores, segundo resultados obtidos com os entrevistados, que acentuam o fato de que a profissão não é mais repassada "de pai para filho", ou seja, não há mais, atualmente, a reprodução familiar da ocupação de pescador no bairro analisado.

Os agentes sociais entrevistados apresentam várias justificativas que explicam esta crise da pesca e da própria identidade do bairro. Uma delas é a questão da legalização. Atualmente não existe mais a organização dos pescadores que existia, no passado. Conforme informaram os entrevistados, a grande maioria desses trabalhadores não tem a sua carteira de embarque assinada, a sua documentação regularizada, de forma a lhes dar alguma garantia, seja ela no momento de sua aposentadoria ou ao longo da sua trajetória profissional. Eles não têm os direitos trabalhistas assegurados. Em caso de acidente, não possuem garantias trabalhistas ou previdenciárias. Geralmente, o registro é feito apenas na Colônia de Pesca, mas não é realizado na Capitania dos Portos. Acredita-se que este desinteresse se manifeste em razão da questão da possibilidade de gerar mais custos, de pagamento dos direitos do profissional da pesca. É compreensível que o pescador prefira trabalhar em outra atividade que não seja a pesca, passando a ter seus direitos garantidos em outra profissão (8 horas de trabalho diário, garantia de aposentadoria etc).

Ouvindo-se os entrevistados, pode-se perceber a falta de fiscalização sobre as atividades de pesca em Jurujuba. Existem muitas irregularidades ocorrendo, muitas vezes, sob condições de "vistas grossas" dos órgãos competentes, que não têm desempenhado a contento o seu papel de fiscalização. Dentre as irregularidades ocorrentes destaca-se a falta de documentação dos pescadores e proprietários de barcos de pesca. Há ainda o problema do tamanho da malha de rede de pesca: tempos atrás, o tamanho permitido para as malhas era de $11 \mathrm{~mm}$, atualmente encontram-se malhas de $4 \mathrm{~mm}$ apenas, e, portanto, significativamente predatórias. Esta prática inviabiliza o desenvolvimento e reprodução de algumas espécies, tais como a sardinha, usada como isca para a pesca do atum.

A sobrepesca é um outro fator responsável pela atual situação do bairro. Constatou-se que a pesca predatória, em conjunto com a poluição das águas da Baía de Guanabara, levou a uma diminuição da quantidade de peixes naquela região.

Atualmente os barcos pequenos fornecem a isca para os barcos grandes, e para isto, utilizam malhas de rede muito pequenas, não respeitando o ciclo de reprodução da espécie, contribuindo, desta forma, para a escassez dos recursos marinhos. 
Em décadas anteriores, as embarcações maiores, chamadas caiçaras, só realizavam a pesca em alto mar, mas atualmente, atuam dentro da Baía de Guanabara, contribuindo para a diminuição das espécies marinhas, por capturarem peixes ainda em fase de crescimento.

Quanto à poluição da Baía de Guanabara, são muitas as suas fontes, destacando-se as fábricas de enlatamento, que possuem uma grande parcela de contribuição para a sua ocorrência. Isto é mais pronunciado nas águas da Baía que banham Jurujuba. Somente após o fechamento destas fábricas foi possível detectar o reaparecimento de algumas espécies marinhas, nas praias de Jurujuba.

Existe também a questão do esgoto local que é lançado diretamente nas águas das praias locais. Enquanto aguardam por efetivas melhorias das condições de saneamento (água e esgoto) do bairro, os próprios moradores vão contornando o problema local, por conta própria, através de formas improvisadas de saneamento, construídas através de mutirões locais.

Diante de tantas dificuldades, atualmente em Jurujuba, um número muito pequeno de pessoas ainda atua na pesca. Os demais trabalham em outras profissões. Os resultados das entrevistas atestam que os próprios pais não mais incentivam seus filhos a permanecerem na pesca. A maioria dos idosos, que já trabalharam na pesca, conseguiu a aposentadoria de pescador, mas os jovens não poderão contar com esse direito, porque dificilmente obterão a documentação necessária para que isto se concretize.

Atualmente, a maioria dos pescadores não sabe fazer o trabalho artesanal com a rede. Constata-se, inclusive, uma perda da memória da pesca artesanal. No passado, à medida que observavam o trabalho do mestre-de-rede, os pescadores aprendiam a fazê-lo. Atualmente, os donos dos barcos pagam diárias àquelas pessoas, geralmente aposentados, que sabem fazer este tipo de trabalho, e aqueles pescadores que não têm esse conhecimento são dispensados. Atualmente, os jovens não querem trabalhar na pesca, não têm estímulo para isto; e não pescam para a sua subsistência. Quando atuam na pesca, geralmente trabalham em outras atividades profissionais, concomitantemente, objetivando complementar os seus rendimentos. Os agentes sociais entrevistados carregam, ainda, um saber prático adquirido e formatado através de suas histórias ocupacionais como pescadores. Este saber faz parte de sua identidade. Um claro exemplo disto encontra-se na fala de um destes, que polemiza o fato de que não basta trabalhar na pesca para ser "pescador", pois o "pescador" precisa dominar os meandros da atividade de forma mais artesanal, conhecendo todas as fases do processo da pesca, desde a confecção da rede, até o momento de "matar" o peixe. Esta identidade que se ancora em um saber específico está, hoje, viva em somente poucos indivíduos, no bairro. 
Em suas discursividades, os agentes sociais entrevistados nomeiam o ciclo de reprodução das espécies de valor econômico e chegam a definir Jurujuba como sendo um "criador" de peixes e de camarões. Com este mesmo saber prático, explicam o fenômeno da diminuição de peixes e conseqüentemente, de pescadores. Sabem que, sem peixes não há pescadores, e que sem novas gerações de pescadores socializados nos mesmos conteúdos identitários, não haverá, em breve, senão traços em Jurujuba da antiga efervescência material e simbólica que foi o motor para uma forma específica de sociabilidade.

\section{4 - CONCLUSÃO}

Este trabalho buscou discutir a degradação sócio-ambiental, sob o ponto de vista da análise da crise da atividade pesqueira, tendo sido, para tal, estruturado um estudo de caso desenvolvido numa comunidade na cidade de Niterói (DUARTE, 1978; SOARES, 2003), onde observou-se as principais fontes do impacto das transformações ocorridas.

Os autores buscaram privilegiar o encontro efetivo entre preocupações de pesquisa e a população de uma área que sofreu intensa degradação ambiental nas últimas décadas. A marca metodológica que se imprimiu considerou fundamental a convivência direta dos autores com os sujeitos sociais específicos do caso estudado.

Neste sentido, aponta-se inúmeros problemas acerca da escassez do pescado e da poluição na Baía de Guanabara. Conclui-se que um elemento fundamental discutido e analisado nos resultados apresentados, consiste na recomendação para que atuais ou futuros projetos voltados para a recuperação ambiental da Baía de Guanabara, ou para a recuperação da atividade pesqueira, levem em consideração o "saber local", construído ao longo do tempo pelos agentes sociais que se reproduzem naquele ecossistema.

\section{REFERÊNCIAS BIBLIOGRÁFICAS}

BOSI, Alfredo. Dialética da colonização. São Paulo: Companhia das Letras, 1998.

DIEGUES, A. C. S. O mito moderno da natureza intocada. São Paulo: NUPAUB Universidade de São Paulo, 1994.

Pescadores, camponeses e trabalhadores do mar. São Paulo: Ática, 1983.

DUARTE, Luiz Fernando Dias. As redes do suor; a reprodução social dos trabalhadores da produção do pescado em Jurujuba. Dissertação (Mestrado em Antropologia Social) Programa de Pós-Graduação em Antropologia Social, Universidade Federal do Rio de 
Janeiro, 1978.

HALL, S. A identidade cultural na pos-modernidade. Tradução: Tomaz Tadeu da Silva e Guacira Lopes Louro. Rio de Janeiro: DP\&A, 2001.

KANT DE LIMA, Roberto; PEREIRA, Luciana Freitas. Pescadores de Itaipu: meio ambiente, conflito e ritual no litoral do Estado do Rio de Janeiro. Niterói: EDUFF, 1997.

PASSANHA, Elina Gonçalves da Fonte. Os companheiros: trabalho na pesca da Itaipu. Dissertação (Mestrado em Antropologia Social) - Programa de Pos-Graduação em Antropologia Social do Museu Nacional, Universidade Federal do Rio de Janeiro, 1977.

SAHLINS, Marshall. O "pessimismo sentimental" e a experiência etnográfica: por que a cultura não é um "objeto" em via de extinção. Mana, Rio de Janeiro, V.3, n. 1, abril de 1997. (parte I,II)

SILVA, Tomaz Tadeu da (org.): HALL, Stuart; WOODWARD. Kathryn. Identidade e diferença: a perspectiva dos estudos culturais. Petrópolis:Vozes, 2000.

SOARES, Maria Teresa Costa. Degradação sócio-ambiental: a crise da atividade pesqueira em Jurujuba - Niterói/RJ. Dissertação (Mestrado em Sistemas de Gestão) - Departamento de Engenharia de Produção, Universidade Federal Fluminense, 2003.

Artigo Recebido em 27/04/04 e aceito para publicação em 15/06/05 